UDK 004.89

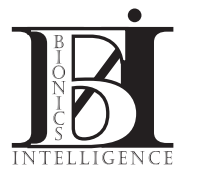

\author{
Bilous N. ${ }^{1}$, Tereshchenko G. ${ }^{2}$, Kyrychenko I. ${ }^{3}$ \\ ${ }^{1}$ Candidate of Technical Sciences, Professor of Software Engineering Department, \\ Kharkov National University of Radio Electronics, nataliya.bilous@nure.ua, \\ ORCID iD: 0000-0002-8850-9316
}

${ }^{2}$ Graduate students of the Department of Software Engineering, Kharkov National University of Radio Electronics, hlib.tereshchenko@nure.ua, ORCID iD: 0000-0001-8731-2135

${ }^{3}$ Candidate of Technical Sciences, Assistant of the Department of Software Engineering, Kharkov National University of Radio Electronics, iryna.kyrychenko@nure.ua, ORCID iD: 0000-0002-7686-6439

\title{
COPYRIGHT PROTECTION USING BLOCKCHAIN
}

This article examines the potential and limitations of blockchain technology and blockchain-based smart contracts in relation to copyright. Copyright has long been enforced through technological means, specifically Digital Rights Management. With the emergence of blockchains, many are now predicting a new era regarding the administration and enforcement of copyright through computer code. The article introduces the technology and related potential and limitations while stressing its capacity to act as a form of normative ordering that can express public or private objectives.

DIGITAL RIGHTS MANAGEMENT, COPYRIGHT, BLOCKCHAIN, SMART CONTRACTS, PRIVATE ORDERING, PERMITTED USES

\section{Introduction}

Current issue for today is who will regulate the author's and property issues in the 21 st century. The matter concerns not only works of art and science, it concerns even your things, houses, motorcycles. Who or what will control the property and legal documents in the 21 st century?

It is clear that this will not deal with the old market with offices and corporations dictating the conditions. Publishers, producers, promoters and PR people will be forced to look for new ways to earn on air and adapt to the growth of individualism, which is so often labeled "Western" and advised to get rid of many religions of the world. A system where the majority has to put up with the rules for the dissemination of information and goods, imposed by several large uncles, is a thing of the past.

And perhaps you ask: why so many people are deprive of work? After all, many will have a hard time, when it is impossible to earn on the fruits of someone else's work and creativity. Well, firstly, while the author receives "interest from sales" the media giant has superprofits, which it is sometimes so convenient to hide. This is not fair to the author. Secondly, if the authors themselves are not against the free circulation of everything being created, and some of them are even actively advocating, we must clearly understand and admit that we have the right to reform [1].

In addition, some products of creativity can impose cryptographic methods of protection. In the New World there will be no bloody revolution, the technology itself will make some ideas obsolete and others will be relevant, and since technology is inextricably linked with progress, if it is not weapon technology, it will only move it forward by overcoming artificial restrictions: superstitions, religion, ideology, dogma, titles, titles, legislative prohibitions, important pathos, and so on.

\section{Blockchain}

Blockchain - is a decentralized database, the storage devices of which are not connected to a shared server. Any member of the system can make records in it, which after verification are automatically displayed on all computers on the network. Thus, the main advantage of the blockchain is the safety of the information stored in it [2]. No one can forge or replace it, as unilateral changes on each of the network devices will require huge computing capabilities that are not available to the ordinary participant of the system. In the field of intellectual property (IP) protection, the technology will provide safe storage and prompt updating of information about any IP objects: from a patent for high-tech development to a musical work.

\section{Copyright protection}

The system for the protection of trademarks and patents is currently based on registers of rights to IP objects maintained by authorized state bodies. It is also important here that when entering the abovementioned registers, non-trivial manual work should be performed to verify the IP object for protection. The system for the protection of trademarks and patents is currently based on registers of rights to IP objects maintained by authorized state bodies. It is also important here that when entering the above-mentioned registers, non-trivial manual work should be performed to verify the IP object for protection. Strange as it may seem, new technologies, some of which are called cryptoanarchic, came to the right holder to help. This is a 
decentralized system for exchanging, storing and processing data. Or about the blockchain. The well-known advantages of the new technology are that it is possible to deposit authorship without the participation of a third party and without binding to geography. In the decentralized registry, you can store information about the output parameters of the author's object, as well as the object itself (or its digital imprint, if you need to save on the volume of the file blockchain). The authenticity of the object is confirmed by a cryptographic guarantee - a kind of digital seal. There are several startups that implement the certification of documents uploaded to a distributed database. Potentially, they will be able to solve, for example, the question of the authenticity of the authorship of photographs, which are purchased in stock shops. Such mechanisms can be used to write to the block and the right to own a licensed software (and check the license by the manufacturer or automatically when connected to the blockchain).

A revolution, or at least tectonic shifts, is called blockchain in the music industry. The fact is that everything related to royalties paid to the author of a musical work is a very complex and often opaque process. Blockchain and smart contracts solve this problem, as they eliminate the functions of organizations managing copyright and related rights - no more mediators, and hence distortions and additional costs. This is especially true for unknown performers who are just starting their career - these musicians simply do not have the money to enter into contracts with major labels.

However, entering into a certain state or non-state register can be useful for a number of purposes, including facilitating the receipt by users of information about the current rightholder. There may well be a prospect for using a detachment [3].

For example, downloading a movie (book, program) from the Internet, you along with it can get information about the current copyright holder and the terms of his public license (that is, how much you have to pay for downloading). If proper software is available, the download itself may be carried out upon payment in accordance with these conditions. Or, based on this technology, you can organize the exchange of electronic copies of movies (books, etc.), if, of course, this is the permission of the original copyright holder. Then users will be able to transfer files to each other (as the bitcoins are being transmitted right now), similar to how a paper book or a movie disc is transmitted. Including for money (real or virtual).

Each content unit has its own price. Actions in many content platforms on the blockchain, for example "Voice", are reduced to money. That is, each unit of text, each photo, a comment in the system is automatically assigned a certain amount. This amount can grow depending on how other users interact with this content: read it or create something new based on it. That is, each unit of text, each photo, a comment in the system is automatically assigned a certain amount

The author can choose the appropriate privacy policy for each content unit. When a user simply enters the block with the author's text, the author receives a reward. When the reader wants to use a fragment of the text for his own purposes, he chooses the appropriate item (if it is provided for by the privacy policy) and the author gets even more reward.

In addition, information about the source (author) of the text fragment will be in the chain with the new content created on its basis. But here is another thing.

Content-platforms on the blockchain themselves monitor the observance of your copyright. After the content unit is created and published in the system, it is assigned a code that is automatically "checked for uniqueness" for all units of the block system. You correctly understood: after adding each new element the whole system is updated.

It's as if Google were updating its search engine after the next page appeared. Only much, much faster. First of all, due to the fact that all data is not on any servers, like Google, but distributed among all participants of the block system. That is everywhere and nowhere at the same time.

Since your most evil critic is yourself in a year, many blockchain based content platforms open up opportunities for editing or deleting blocks with content without destroying the whole chain. Such developments are, for example, in Bandcamp and Accenture. That is where, the block will disappear, but if the deleted text fragment has already been used somewhere, information about you as an author will be preserved. This is what Americans call "legacy", a legacy. The bad news: no one will forget what you wrote that night. Good: you can manage content as a valuable asset, bequeathing it to heirs.

The principle of blockchain solves a very important issue in the world of information domination over the individual: how to preserve mercantilist benefits and leave a trace in history without investing in a PR brand, simply doing its own thing. In order to earn more, the author can assign any meta tags to the content units, improving their visibility in the system, but in the top of the tape there will still be texts with the greatest number of interactions from real users-backers. No cheat from the bots.

Blockchain can offer revolutionary changes for marketing, but this has never come into fashion among marketers and has not become a trend, like Snapchat and online video. 


\section{Future of blockchain}

The chain of blocks or blockchain of bitcoin is well known due to its use as a kind of ledger for dealing with digital currencies. At the same time, this technology has the potential to be used to solve other, very radical, tasks. In particular, he gives us an idea of how bitcoin might one day affect the scope of intellectual property and intellectual rights.

And what about the disputes between the numerous "authors"? Constantly someone is suing someone for property or copyright, although the dispute can be resolved by a timely small entry in a block of several tens of kilobytes. Authors of works can prove authorship with the help of this system. It will no longer be necessary to resort to special complicated legal manipulations. It is enough to create in the locker, which is guaranteed never to be changed or erased, an encrypted entry with the first, seventeenth and last page of your book, for example. Leaving or receiving data, according to which you can be accurately acknowledged by the author of this record.

In the not too distant future, mankind will go on to write down not only pieces of its creativity at a certain time in the structure of the detachment, but also the management of the "logs" of life: incidents, data, discoveries, laws and rights will be written into the blockchain. It is not at all necessary to have an archive building or a state "office" servicing owners' catalogs. Governments in general pretend that they do not understand: maintaining secret documentation in an encrypted block system helps to avoid leakage.

Thus, it is possible to exclude the influence of centralized bodies - all-pervasive and senselessly harsh - on consumers and creators of content and products. The severity of corporations is caused by the desire for power, and the people always, at least subconsciously, strive for freedom. Imagine, by the way, how much money for the budget we will save! We do not need a building, furniture, light and water, computers and food in order to build archives and offices, hire staff there. Confirm the right to own creativity and inventions can be using a smartphone.

How do you model a step-by-step creation of a real hit, where do developers, actors or stunt people consult about all the details of the game, the movie or even the play with bitcoin investors? Already today, just adding a button "type" to our torrent distributions and receiving constructive comments, we partially step on this innovative path [4].

Your ideas can no longer be stolen! Everyone will be able to record unconditional priority and authorship of both artistic and scientific works. The world "Bit-net" will provide an opportunity to link real assets and assets to the blockchain. Truthfulness is assured, and a whole bunch of bureaucrats, lawyers and other air sellers are left without work. But the work will appear among millions of authors, inventors, artists around the world.

Some believe that their creativity is of no interest to anyone, but this is far from true! It is exclusive consumption that will become a characteristic feature of the first bitcom users. Authors of news, scientific, entertainment and other content, rare goods and services have already learned to advertise themselves through the Internet and attract public attention, at the same time "burying" television and physical advertising.

Now it's time to start taking real money for your efforts. Your audience is not limited to the territory of your native city or home state. Why should its finances be limited to this territory?

While bitcoins will flow into your pockets, copyright will undergo some "moral" changes, so that suddenly it does not turn out that bitcoins flow into the pockets of some other company that stole your idea. To get acquainted with works of art and science will be completely free. As a consumer, you will be able to search, read, watch, listen and copy to yourself anything you like without restrictions and legitimately. In some corners of the Internet, similar services are already available even in the CIS, payment? Bitcoins, of course! If you think that only drugs are sold for crypto currency, you live in 2009.

As the author of music, books or games, you can make a profit and "tip" from people from all over the planet, in volumes that are still difficult to predict. Not only will you receive material support from the fan community, you will also multiply it. Since the rate is very variable, people's interest will only grow, and your current "state" of $\$ 5$ tomorrow may turn into $25 \ldots$ or 50 .

The Internet bit of the future will allow ordinary people with small and medium income to get a chance to enjoy the results of creative and intellectual work of all ages, at the same time offering the whole world their services. Not only classics, but modern works will be available anywhere in the world. The importance of a total rethinking of copyright in the 21st century is great, because now there is a huge amount of priceless information, which should be caught literally "on the fly". The first thing that comes to mind is that the proof of existence can be used to confirm the authenticity of the certificate of property without revealing its contents.

You put a hash next to the link to download the file and check the hash yourself. Even if someone breaks into your server, it will not be able to change it. Using this method, you can unambiguously prove that the document or part of the code was checked at a particular time, and the global database of transaction accounting in the Bitcoin network is ideally suited as a means of its implementation. These are just some of the directions for applying this service. 
Taking into account the described potential of services, which are possible for implementation on the basis of evidence of existence, this principle may prove even more valuable than the cost of bitcoin, on which most investors are obsessed today.

Digital property can sometimes be viewed as intellectual, and blockchain technology can prove ownership of such property. For example, if you write an article or you have an idea suitable for a patent, in some cases you have to prove that you owned this idea or document earlier than someone else. A check is an example of the potential of a blockchain beyond simple monetary innovation.

Now you need someone to be a third party in proof of identity - like Facebook, Twitter or Google. You could very well do the same, using the architecture of the blockbuster.

\section{Blockchain in economy}

The technical side of the invention of Satoshi Nakamoto will allow you to develop business in different directions, this will not be exactly for your competitors, and this need not be reported to the authorities. When you build a business, people will buy everything that you invent and offer, if it is useful and interesting. But you need to prove that you are the author. Blokchain provides such a proof, and Bitkoyn is a method of anonymous international payments (anonymous means very fast). In addition, taking the crypto currency for payment today, you create a powerful foundation for your reputation and wealth tomorrow. Do you think that the pioneers of the Internet are rich? What can you read about the first directors, scientific innovators, cosmonauts? And what about the conquerors of America? Sometimes for success it is necessary not to run faster than everyone, but to run out early, and to do it as uniquely as possible.

It is important, however, to understand that the technology of blockchain (the system of keeping the register of rightholders) does not by itself protect against piracy. Since books and films must eventually be converted into a human-readable form, it seems that you can always make an unprotected copy from this form [5].

So in the final account for protection still have to go to the courts, and records in distributed registries can then be used as evidence. Well, that, of course, if the judge knows the word "blockchain".

\section{Blockchain Technologies in the Copyright Domain}

The potential of blockchain as a general-purpose technology is currently being experimented with in many domains, including copyright law. Over the past months and years variegated suggestions as to how the technology could be deployed for the management of copyrighted works and neighboring rights objects have been voiced by industry and in the academic literature. In this section, we provide a cursory overview of expected application of these technologies. We organize the following overview around three main drivers leveraging the main characteristics of blockchain technologies. The first driver revolves around the potential capacity of blockchain technology to precisely identify a digital asset and thereby counter the problem of digital "fluidity". The second driver is related to the ability of blockchain technologies to foster transparent and disintermediated transactions. The third axis focuses on the potential of blockchains to be developed as a DRM system. Finally, in the second sub-section we introduce some structural limits of blockchain technologies such as the so-called "garbage-in garbage-out" problem [6].

\section{Prospects for Application}

Firstly, it has been argued that DLT could be used to create artificial scarcity in the digital market. Indeed in the copyright domain tokens may represent various elements including a copy of a protected work. This may solve a number of issues related to the fluidity of digital objects and create new business models. This may lead to the commodification of digital works and thereby allowing the creation of new markets. Some projects have already been implemented, in particular in the field of artworks leveraging the fact that blockchain technologies make digital artworks more attractive for collectors. It has also been speculated that these developments create the necessary preconditions for flourishing, technologically-enabled secondary markets for digital content.

DLT may also enable the precise tracking of certain digital assets (through tokens) that could be used as evidence of authorship and provenance. In relation to attribution, hashing can create a unique fingerprint of copyrighted material that allows verification of authorship and that the creative work existed at a given time without revealing the actual contents. The hash allows monitoring of provenance in through recording ownership and usage. DLT has been presented as a "revolution in how to keep track of rights". Tokens can encode information including the terms of use of protected material (such information can be mentioned under the definition of RMI). For unregistered intellectual property (IP) rights such as copyright and neighboring rights, blockchain technologies offer the benefit of providing a time-stamped record of its conception, use and qualification requirements. For example, the hash may facilitate evidence in court cases concerning copyright authorship and violation of the terms of use [7].

Blockchains' characteristics provide an opportunity to conceive of a global registry for copyright and neighboring rights. Indeed only the existence of a global registry holding RMI would allow for the development 
of potential benefits into real benefits of blockchain and smart contracts as described in the following paragraph. In this regard it is worth mentioning the project currently implemented by PRS for Music, ASCAP and SACEM which aims at improving data accuracy for right holders. This point will be further developed in the next section.

Secondly, there is the prospect of transparency and cost savings related to smart contracts as once a user purchases the digital asset from a website, the smart contract can be triggered immediately so that all other actions - e.g. payment of royalties to right holders - are automated. Combined with digital currencies, this enables micropayments, which could change pricing models in relation to copyrighted materials. Micropayments - meaning the payment of a small sum, such as EUR 0002 - is currently not an economically viable solution as transaction fees exceed the price itself. The advantages of this method are manifold: "the smart contract facilitates microtransactions at little to no fee, and payment is divided nearly instantaneously - per the strict logic of the smart contract code - and is immediately disbursed to the musicians in amounts of less than $\$ 0.01$ ”. This innovation could also serve to enable an instantaneous, fairer and transparent remuneration of authors and artists. To illustrate, Ujo Music uses smart contracts to facilitate the sale of digital music files. The payment of a certain sum to download a song triggers the smart contract, which divides payment between the various contributors to the song. Notably, this transaction can theoretically occur without the need for a traditional intermediary such as a publisher, a music label or performance organization. Notwithstanding, these platforms still constitute a new form of for-profit intermediaries so that it is still to be determined what economic impact such solutions will eventually have. Thus blockchain promises allowing artists to independently determine prices and individually license their works in a "direct-to-fan" fashion. This appears to offer some remedies for the digital era's challenge of easy unauthorized access to and distribution of copyrighted works.

Some hope that smart contracts will generate disintermediation which would affect incumbents at different levels, including: (1) publishers and music labels, (2) collective management organizations (CMOs), and (3) online platforms. According to others, complete disintermediation is unlikely as blockchains may simply introduce new stakeholders. In the field of online music many blockchain projects promise disintermediation between artists and audience. Yet in reality such actors can be seen as new intermediaries. Indeed, while current discourse frequently envisages authors and artists themselves programming their smart contracts and thus directly defining terms of use, it appears that for numerous reasons of an economic, cultural and technological nature, this is an unrealistic prospect. Sometimes the role of intermediaries goes further than the mere management of legal tools being more related to marketing strategies. In any case, for the "direct-tofan" model to take hold, solutions need to be devised that can provide a user-friendly form of smart contract management, which does not require the user to personally code the smart contract. It should be noted that some are already working on corresponding solutions [8].

Smart contracts may also play a role in standardizing licensing terms and conditions for copyright works across uses and jurisdictions. Standardized smart contracts, the terms of which can be described in comprehensible language, augment transparency and reduce barriers to using contracts for transactions. The technology could also be used to generate custom smart contracts with the terms of license payment and even its split between various beneficiaries.

Thirdly, some believe that DRM itself may be disrupted by blockchain technology. A number of projects are already underway in this domain. Sony recently applied for a patent for a DRM solution based on blockchain. Kodak launched a similar project, KodakOne, which is aimed specifically at photographers and agencies. Whereas over one trillion photos are uploaded to the web each year, most of them fall into the category of orphan works because it is burdensome for photographers to administer image licensing, infringement detection and reporting. KodakOne seeks to change this by creating an image rights management platform, combined with tokens (to manage instantaneous royalty payments) and smart contracts (to document licenses).

These early initiatives underline that blockchain can serve to create a hard-to-amend record of initial ownership with smart contracts being encoded to license the use of copyrighted works. Here, smart contracts are deployed to automate and standardize copyright-related transactions (such as use and exploitation of content as well as remuneration) in relation to blockchainbased tokenized elements. 144 Smart contracts would be modelled to hold, execute and monitor contractual code. The idea is that smart contracts would be used to establish and self-enforce copyright agreements such as licenses, and provide information about rights in copyrighted materials.

Highlighting that traditional DRM solutions rely on single points of failure, are expensive, can be overcome by a single hacker and interfere negatively with consumer expectations, blockchains' resilience-throughreplication is appealing. It is important to note, however, that automated licensing through smart contracts is not to be confused with traditional DRM systems which always involve control of access and use of digital 
subject matter. Blockchains may offer right holders greater security and stronger protections against possible attackers including copyright infringers that seek to access the digital asset. User rights would be encoded on a blockchain. Connected systems would then verify these rights and decrypt the related copyrighted content where appropriate. A smart contract would then be used to allocate access to the digital asset via tokens (such as bitcoin, ether, etc.) that reside on the chain, the role of which consists in facilitating remuneration and payments.

Blockchains do not hold the copyrighted digital asset itself in light of the technology's limited processing capabilities but rather facilitate a smart contract that contains information regarding related rights and permissions. However, when users use a work through their device, they trigger communication with the distributed ledger. The DRM system can scan the record for the necessary permission and give the user access to the acquired work. For example, if the user has purchased a limited-duration license, the system can consult a trusted timeserver and compare the time with the contract terms coded on the blockchain and take away access once the user's license has expired. Blockchain technology could therefore control use-rights and just as is the case with current DRM systems, smart contracts do not necessarily encode legally permitted copyright uses. We will return to this point in the following section.

After having summarized the main themes revolving around copyright management by means of blockchain uses, it is worth stressing some structural limitations of blockchain technologies [9].

\section{Smart Contracts}

In essence, a smart contract is self-executing computer code that automatically processes its inputs when triggered. It is essentially a small computer program that is deployed on a blockchain. Thus while smart contracts are currently being avidly discussed in relation to blockchain, similar mechanisms have been used for a long time, also by DRM systems. As explained, DRM technology essentially embedded copyright law into digital files by limiting the user's ability to view, copy, play, print, or otherwise alter the works. For example, digital audio files encrypted with DRM technology were not subject to the double-spending problem because they contained a basic smart contract, which referenced a centralized network (that is, for example, Apple's server programmed to enforce the iTunes Store Terms and Conditions). Beyond this rather basic definition there is little consensus as to what this terminology really refers. It is worth noting that depending on the adopted definition, smart contracts are not necessarily linked to blockchain technology. Given that they are discussed in relation to distributed ledgers in the literature we introduce below, we will also examine them as such here.

To some, a smart contract is simply a piece of computer code with specific characteristics. Vitalik Buterin portrays smart contracts as "cryptographic 'boxes' that contain value and only unlock it if certain conditions are met”. In the blockchain context, a smart contract is "programmed logic that runs on a ledger-like distributed system in response to transaction submission". From a technical perspective, smart contracts are thus simply computer programs that can be consistently executed by a network of computers without the need for an intermediary. Because of their distributed nature and thus guaranteed execution, smart contracts are resilient to tampering, which makes them appealing in many scenarios including the transfer of value.

Yet, because these technical tools can be relied upon to automate transactions typically governed by contract law (such as value transfers) smart contacts can be useful tools in a contractual setting. Nick Szabo indeed coined the term "smart contract" in 1994, to denote "a set of promises, specified in digital form, including protocols within which the parties perform on these promises". Szabo envisaged the creation of computer software resembling contractual clauses to connect parties in a fashion that would make it difficult for one party to unilaterally terminate an agreement. Seen from this perspective, a smart contract can be a Ricardian contract, the objective of which is to create contracts that can be read by humans and machines alike. Indeed to some, a smart contract is "a computer program that both expresses the contents of a contractual agreement and operates the implementation of that content, on the basis of triggers provided by the users or extracted from the environment".

The main value proposition of smart contracts is that of their automated execution. As second-layer applications, smart contracts benefit from the tamper-proof nature of the underlying blockchain infrastructure that anchors their automated execution. Given that many blockchain nodes run smart contract code, it "is not controlled by - and cannot be halted by - any single party". Smart contracts execute automatically and cannot be halted unless this option is specifically built into the code. This enables transactions in situations devoid of human or institutional trust, lowers transaction costs and reduces counterparty risk and interpretative uncertainty. Once an agreement has been translated into code, the intervention of a party or intermediary (other than the respective oracle) triggering contractual execution is replaced by the software's automated execution.

Where smart contracts are used to automate the execution of contractual obligations, performance is thus hard-wired into the code. For example, the software can be used for the automatic transfer of collateral in 
the event of default. Automated execution of course not only provides benefits but also disadvantages. Where software executes automatically, unwanted transactions can no longer be rolled back. This can be problematic, such as when a party lacks legal capacity or a party decides to default on its obligations. Modifications, such as those mandated by law or court decisions also cannot easily be accommodated. Through these characteristics, smart contracts promise to trigger efficiency gains particularly attractive in commercial settings, including in relation to copyrighted materials [10].

\section{References}

[1] Gates $M$. Blockchain: Ultimate guide to understanding blockchain, bitcoin, cryptocurrencies, smart contracts and the future of money. / Mark Gates., 2017. - 125 p.

[2] Wright A. Blockchain: Uncovering Blockchain Technology, Cryptocurrencies, Bitcoin and the Future of Money: Blockchain and Cryptocurrency Exposed (Blockchain and Cryptocurrency as the Future of Money / Alan Wright., 2017. - 130 p.
[3] Buterin $V$. The Business Blockchain: Promise, Practice, and Application of the Next Internet Technology / V. Buterin, W. Mougayar., 2016. - 208 p.

[4] Vigna P. The Truth Machine: The Blockchain and the Future of Everything. P. Vigna, M. Casey., 2018. - 302 p.

[5] Swan M. Blockchain: Blueprint for a New Economy / Melanie Swan., 2015. - 152 p.

[6] Williams S. Blockchain: The Next Everything / Stephen Williams., 2019. - 208 p.

[7] Antonopoulos A. Mastering Bitcoin: Programming the Open Blockchain / Andreas Antonopoulos., 2017. - 416 p. - (2nd Edition).

[8] Tapscott A. Blockchain Revolution: How the Technology Behind Bitcoin and Other Cryptocurrencies Is Changing the World / A. Tapscott, D. Tapscott., 2018. - 432 p. (Reprint edition).

[9] Werbach $K$. The Blockchain and the New Architecture of Trust (Information Policy) / Kevin Werbach., 2018. $-344 \mathrm{p}$.

[10] Wright A. Blockchain and the Law: The Rule of Code / A. Wright, P. De Filippi., 2018. - 312 p.

The article was delivered to your editory stuff on the 17.04.2019 